\title{
Oxytocin and Uterine Atony during Cesarean Section
}

\author{
Loutfi Guennoun Abdelmounaim1, A. Rjafallah², N. Nhiri², N. Biougnache ${ }^{2}$, R. Benafitou ${ }^{3}$, \\ R. Barka4, Y. Bouferma5, S. Habib Rabbi6, 0. El Ayoubi', 0. Alaoui ${ }^{7}$, S. Mesnane7, \\ M. Khouchoua ${ }^{7}$, S. Lafkir ${ }^{7}$
}

${ }^{1}$ Gynecology and Obstetrics Department, Sidi Said Hospital, Meknes, Morocco

${ }^{2}$ Gynecology and Obstetrics Department, Pagnon Hospital, Meknes, Morocco

${ }^{3}$ Resuscitation Anesthesia Department, Pagnon Hospital, Meknes, Morocco

${ }^{4}$ Head Nurse of Gynecology and Obstetrics Department, Pagnon Hospital, Meknes, Morocco

${ }^{5} \mathrm{Head}$ of the Admissions Department, Sidi Said Hospital, Meknes, Morocco

${ }^{6}$ Master in Communication Moulay Ismail Meknes University, Meknes, Morocco

${ }^{7}$ Medical Administration and Epidemiological Services, Meknes, Morocco

Email: loutfimounaim@hotmail.com

How to cite this paper: Abdelmounaim, L.G., Rjafallah, A., Nhiri, N., Biougnache, N., Benafitou, R., Barka, R., Bouferma, Y., Rabbi, S.H., El Ayoubi, O., Alaoui, O., Mesnane, S., Khouchoua, M. and Lafkir, S. (2021) Oxytocin and Uterine Atony during Cesarean Section. Open Journal of Obstetrics and Gynecology, 11, 815-822. https://doi.org/10.4236/ojog.2021.116075

Received: May 18, 2021

Accepted: June 26, 2021

Published: June 29, 2021

Copyright $\odot 2021$ by author(s) and Scientific Research Publishing Inc. This work is licensed under the Creative Commons Attribution International License (CC BY 4.0).

http://creativecommons.org/licenses/by/4.0/ (c) (i) Open Access

\begin{abstract}
In our medical practice, in particular obstetrics, it is difficult to change certain consolidated dogmas, but the necessity and the current situation of our obstetrical exercise pushed us to find new technical supports, to make the exercise of our specialty as stripped of pitfalls as possible. Our work is summarized in a prospective comparative study, aimed at evaluating the existence or not of a difference between the administration of oxytocin just before the hysterotomy in a cesarean section and its administration after fetal extraction. We used a set of criteria to include patients in our study. This study took place over a period of one year (2020) in the Mother and Child regional center, in Meknes Imperial city, Morocco, involving a total number of 364 patients. With a group A comprising 176 patients 48\% (176/364) who received oxytocin just before the hysterotomy and a group B of 188 patients $52 \%$ (188/364) who received it classically after fetal extraction. The difference was very significant as detailed in the article. Conclusion: the very convincing results of our study and the difference between the two groups, allowed us to demonstrate the effectiveness of our process and to endorse its use in our routine practice, with the perspective of conducting a prospective randomized study on a larger series.
\end{abstract}

\section{Keywords}

Oxytocin, Cesarean Section, Uterine Atony, Postpartum Hemorrhage 


\section{Introduction}

Oxytocin is a neuropeptide secreted by the paraventricular and supraoptic nuclei of the hypothalamus and excreted by the posterior pituitary which acts primarily on the smooth muscles of the uterus and mammary glands [1]. This hormone behaves in the brain like a neuropeptide. It could inhibit, via the gabaergic system, the activity of the limbic amygdala which is involved in the detection of fear [2]. At the same time, it promotes the protective behavior of the mother towards her young, via the dopaminergic system. In men, oxytocin has been shown to have an effect on confidence, empathy, generosity, sexuality, marital and social relations and responsiveness to stress. It would even have a beneficial effect in cases of autism, social phobia and depression [3]. The physiological importance of oxytocin was first described in the early 1900s, when biologists discovered that the compound stimulates uterine contractions and lactation [4]. And more precisely Henry Dale is the first to have demonstrated the contractile properties in pregnant cats of a substance produced by the pituitary gland. The isolated molecule was marketed in 1927 under the name oxytocin. And since then it has been prescribed for childbirth in humans [5]. It would take nearly another half century to uncover oxytocin molecular structure-a nine-amino-acid sequence and 30 years more to demonstrate its potency in regulating social behavior [6]. Concerning maternal Care: oxytocin plays an evolutionarily conserved role in regulating several facets of maternalism, including lactation, parturition, and maternal behavior [4] [7]. Because they display strikingly different patterns of maternal behavior, rats and sheep (Ovis aries) serve as particularly important models for understanding oxytocin's role in different aspects of maternal care. While female rats indiscriminately nurture any conspecific infant throughout the post-partum period, female sheep and other precocial mammals develop a highly selective preference for their own offspring; thus, rats have been used to investigate maternal attraction to offspring, while sheep have been used to examine the processes underlying selective maternal recognition [8]. During pregnancy: Oxytocin is present in maternal plasma throughout pregnancy at a level of approximately 25 $\mathrm{pg} / \mathrm{ml}$. The amount of plasma oxytocin is stable during pregnancy and does not increase as childbirth approaches. On the other hand, under the effect of increasing estrogen impregnation, the number of uterine oxytocin receptors increases considerably at the end of pregnancy, until it is multiplied by 100 and reaches a maximum in the beginning of labor. This phenomenon induces an increase in the sensitivity of the uterus to oxytocin and participates in the mechanisms of parturition. Labor begins when the concentration of oxytocin receptors exceeds a critical threshold, from which uterine contractions are initiated by the usual plasma concentration of oxytocin [9]. In addition to all its actions, oxytocin retains an action of capital importance in obstetrics and which lies in its use to avoid uterine atony, which is the cause of more than $80 \%$ of postpartum hemorrhages [10]. Its injection, especially by direct intravenous or 
by rapid perfusion, makes it possible to support uterine retraction, while emphasizing the advantage of the precocity of this administration to have the benefit of prophylaxis: at the time of the release of the anterior shoulder in case of vaginal delivery [11] [12] or after extraction of the baby in case of cesarean section [12] [13], but in our team we noticed the persistence of a considerable number of predictable uterine atonies leading to postpartum hemorrhage. We then tried the administration of oxytocin a little earlier in our cesarized patients (just before making the hysterotomy incision), with very conclusive results. To corroborate our observation, we carried out this comparative prospective study.

\section{Materials and Methods}

Our study is spread over a period of one year (From: 01.01.2020 to 31.12.2020), involving 364 cesarized patients in the regional Mother and Child hospital in Meknes imperial city in Morocco. With group A comprising 176 patients 48\% (176/364) who received 10 international units of oxytocin by direct intravenous injection just before the hysterotomy and group B of 188 patients 52\% (188/364) who received it typically immediately after fetal extraction. These patients were selected on the basis of a set of criteria namely: all the circumstances that could contribute to uterine atony such as: Hydramnios, macrosomia, polymyomatous uterus, long labor, great multi-parity, dynamic dystocia, mechanical dystocia, twin pregnancies after extraction of the 1st twin, history of postpartum hemorrhage, preeclampsia, retro-placental hematoma, low inserted placentas, maternal age over 35 and elective cesarean sections. to minimize bias in our study we tried to have two groups of patients as homogeneous as possible. These inclusion criteria in the study were collected and recorded in the patient files on admission when it was an identifiable factor during the admission examination or on the basis of the clinical data recorded during labor in the delivery room. The rest of the data was collected from the findings recorded in the Caesarean section register in the operating room. We organized ourselves into three teams comprising a gyneco-obstetrician, an Admission midwife, a delivery room midwife and the operating room team. Our patients were included in our study at random, it was sufficient that the inclusion criteria were met. The difference in number between the two groups is due to the fact that the majority of patients were recruited mainly during the three gyneco-obstetricians on call, knowing that the flow of parturients differs from one guard to another.

\section{Results}

Our series includes: 364 cesarized patients, with 2 groups, recruited on the basis of the aforementioned inclusion criteria with a very representative sampling of the loco-regional population. The socio-demographic characteristics of patients in both groups are described in Table 1. 
Table 1. Socio-demographic characteristics of the patients surveyed.

\begin{tabular}{lcc}
\hline & Group A patients & Group B patients \\
\hline MARITAL STATUS: & $\underline{161}$ & 174 \\
\hline . Married: & $\underline{9}$ & 10 \\
. Divorced: & $\underline{6}$ & 4 \\
. Single: & & \\
PLACE OF RESIDENCE: & 92 & 102 \\
. Urban: & 48 & 44 \\
. Rural: & 36 & 42 \\
. Other cities: & & \\
EDUCATIONAL LEVEL: & 51 & 62 \\
. No: & 60 & 44 \\
. Primary: & 43 & 52 \\
. Secondary: & 22 & 30 \\
. Higher studies: & & \\
SOCIO-ECONOMIC LEVEL: & 96 & 102 \\
. Modest: & 78 & 82 \\
. Medium: & 2 & 4 \\
. High: & & 169 \\
ETHNIC GROUP: & 164 & 19 \\
\hline . Morocco: & 12 & \\
. Sub-Saharan refugee: & &
\end{tabular}

Clinically we observed 3 uterine atonies (1.7\%) on the 176 patients in group A without inertia, versus 27 (14\%) on the 188 patients in group B including 11 inertias $(11 / 188=6 \%)$, distributed as it is specified on Table 2 .

Table 2. Distribution of uterine atonies and inertias in the two groups according to the inclusion criteria in the study.

\begin{tabular}{|c|c|c|c|}
\hline Inclusion criteria & $\begin{array}{c}\text { Groupe A } \\
\text { Uterine atony }\end{array}$ & $\begin{array}{c}\text { Groupe B } \\
\text { Uterine atony }\end{array}$ & Uterine inertia: $\mathrm{A} / \mathrm{B}$ \\
\hline Hydramnios & - & 1 & - \\
\hline Macrosomy & - & 2 & $0 / 1$ \\
\hline polymyomatous uterus & - & 1 & - \\
\hline Long labor & - & 2 & $0 / 2$ \\
\hline Great multiparity & . 1 & 3 & $0 / 2$ \\
\hline Dynamic dystocia & - & 2 & - \\
\hline Mechanical dystocia & - & 4 & $0 / 1$ \\
\hline Multiple pregnancies & - & 1 & $0 / 1$ \\
\hline Postpartum hemorrhage antecedent & - & 1 & $0 / 2$ \\
\hline Préeclampsie & - & 3 & - \\
\hline Retroplacental hematoma & 2 & 3 & $0 / 2$ \\
\hline Low inserted placenta & - & 1 & - \\
\hline Maternal age $>35$ years old & - & 1 & - \\
\hline Elective cesarian section & - & 2 & - \\
\hline Total & . 3 & 27 & $0 / 11$ \\
\hline
\end{tabular}


These 11 group B uterine inertias were observed in 2 large multiparous patients, 1 patient following mechanical dystocia, 2 cases in patients with a history of postpartum hemorrhages, 2 cases following cesarean sections for retroplacental hematoma, 2 cases following a long labor, 1 inertia during an intervention for twin pregnancy and the last following a cesarean section for macrosomia. These uterine inertias benefited from surgical supplements: isthmic plication of the uterus (Procedure A by Loutfi) [14] or a large uterine vascular ligation on both sides (Procedure B by Loutfi) [14] or both techniques at the same time without having to perform a hemostatic hysterectomy, as specified in Table 3.

Table 3. Surgical techniques used to overcome group B uterine inertia.

\begin{tabular}{ccc}
\hline $\begin{array}{c}\text { Isthmic plication of the uterus. Large uterine vascular ligation } \\
\text { (Loutfi Procedure A) }\end{array}$ & Procedure A + Procedure B \\
\hline 5 & 4 & 2 \\
\hline
\end{tabular}

The age of the patients was comparable in the two groups, as specified in $\mathrm{Ta}$ ble 4.

Table 4. Distribution of patients according to age in the two groups.

\begin{tabular}{ccc}
\hline Age of patients & Group A & Group B \\
\hline $\mathbf{1 8}-\mathbf{2 0}$ & 18 & 16 \\
$\mathbf{2 0}-\mathbf{2 5}$ & 48 & 54 \\
$\mathbf{2 5}-\mathbf{3 0}$ & 35 & 38 \\
$\mathbf{3 0}-\mathbf{3 5}$ & 29 & 31 \\
$\mathbf{3 5}-\mathbf{4 0}$ & 28 & 23 \\
$\mathbf{4 0 - 4 4}$ & 18 & 26 \\
\hline
\end{tabular}

As shown in Table 4 we can see that the ages of the patients in the two groups were comparable, so we have avoided a very significant bias, because the mother's age is recognized as one of the factors most related to maternal morbidity, independently of the parity by taking as a reference patients whose age is between 25 and 29 as described in the literature [15].

For more details regarding the patients who had presented uterine atony complicated or not by uterine inertia, we have: In the criterion of hydramnios, one patient in group B was diabetic and presented uterine atony on chronic hydramnios. We also have in this 2 nd group 2 frank macrosomies with respectively a uterine height of $41 \mathrm{~cm}$ having given birth to a boy of $5600 \mathrm{~g}$ and the second patient with a uterine height of $38 \mathrm{~cm}$ having given birth to a girl of $4800 \mathrm{~g}$, the first presented uterine atony and the second uterine inertia. We note a patient with a polymyomatous uterus in group B who presented uterine atony and the indication for cesarean section in this case was the presence of a myoma previae. In the indication: long labor, we have 2 cases of uterine atony, both cases progressed to uterine inertia. Concerning great multi-parity criterion we have: 1 pa- 
tient in group A, who was at her 5th pregnancy and who presented uterine atony and 3 patients in group $B$ who were respectively at the 8th pregnancy and presented a uterine atony, 7th pregnancy for the 2 nd which presented uterine inertia and the last one was at her 8th pregnancy and presented uterine inertia. In the category: dystocia, we note 2 dynamic and 4 mechanical, respectively being 2 hypercinesias not regulated by medical treatment and 4 fetopelvic disproportions. In the criterion of multiple pregnancies, we had uterine atony in a twin pregnancy in the 2nd group, which was complicated by uterine inertia surgically treated by Loutfi isthmic plication coupled with bilateral uterine vascular ligation according to the same author. For patients with a history of postpartum hemorrhage, as described above, we had 2 cases of uterine inertia and 1 case of atony which responded well to medical treatment. In cases of preeclampsia, we had 3 uterine atonies, effectively managed by utero-tonic treatment. For the retroplacental hematoma, there were 2 patients in group A who had uterine atony and 3 patients in group B, 1 of whom had uterine atony and the other 2 presented uterine inertia. Regarding the placenta low inserted criterion, only one patient in group B presented a uterine atony. Regarding the indication: Elective Caesarean sections, we had 2 patients in group B who had presented uterine atony and the respective indications for their interventions were: Narrow pelvis for the first one and scarred uterus + narrow pelvis for the second.

\section{Discussion of the Results}

Our hospital is a regional structure which serves a perimeter of $70 \mathrm{~km}$ around with 7 small towns, 13 villages, with 12,000 deliveries on average per year. Our patients are very heterogeneous, with a very varied obstetric pathology every day. Only 4 years ago we had slightly increased morbidity indices, this prompted us to try to adapt our practice to improve our performance. The most important concern that we meet and fear is postpartum hemorrhage. We then decided to carry out this study. We have 2 homogeneous groups, with patients that we recruited prospectively during the respective guards of the three Gyneco-Obstetricians participating in this study. It is useful to specify that we did not randomize, because we would have had to mobilize an administrative team at night, but this privilege was not allowed to us, this is a reproach which could decrease the degree of proof of this study. But despite this we were lucky to have very conclusive results. We easily notice the high number of uterine atonies in group B compared to group A (1.7\% VS 14.4\%) with a ratio of 8.5 times greater in the second compared to the first one. As for the uterine inertias, we find 11 uterine inertias 6\% (11/188) in group B versus no patient in group A. This rate of uterine inertias although it remains in the average of what is described in the literature (3\% - 15\%) [16] It is high compared to group A where there is no inertia. However, the two groups of patients are comparable in their inclusion criteria, the techniques for performing cesarean sections were the same (according to Pfannenstiel), although there are no arguments to favor one cesarean technique 
over another. To prevent postpartum hemorrhage according to the literature [17]. Care was also taken to avoid manual delivery and we were satisfied with delivery by controlled cord traction because, according to experts [17], it would be associated with less blood loss than the first. This harmonization of treatment and inclusion criteria was intended only to highlight the impact of the timing of the injection of oxytocin (just before fetal extraction vs just after) and this difference is clearly put. evidently, with the absence of uterine inertia in the patients of group A and the frequency 8 and a half times more in group B compared to the first.

\section{Conclusion}

Although our study was prospective, it retains the limitation of not being randomized and we have explained why in the paragraph discussing the results. but nevertheless, it emerges from our study that there is a real interest in broadening the sampling of patients as well as the inclusion criteria in order to be able to adopt the option of injection of oxytocin just before performing the hysterotomy and therefore fetal extraction in all cesarean sections in our structure gave the impact of this change in the timing of administration of oxytocin, on the significative decrease in the occurrence of atonies as well as uterine inertias while keeping a reserve in extreme cases where we would have to make versions by endo-uterine maneuvers.

\section{Conflicts of Interest}

The authors declare no conflicts of interest regarding the publication of this paper.

\section{References}

[1] Wikipedia. https://fr.wikipedia.org/wiki/Ocytocine

[2] Viviani, D. and Stoop, R. (2008) Opposite Effects of Oxytocin and Vasopressin on the Emotional Expression of the Fear Response. Progress in Brain Research, 170, 207-218. https://doi.org/10.1016/S0079-6123(08)00418-4

[3] Martin-Du Pan, R.C. (2012) Oxytocin: The Hormone of Love, Trust and Social Bond. Clinical Use in Autism and Social Phobia. Revue Médicale Suisse, 8, 627-630.

[4] Ondrasek, N. (2017) Oxytocin. In: Vonk, J. and Shackelford, T.K., Eds., Encyclopedia of Animal Cognition and Behavior, Springer International Publishing AG, Berlin, 1-10.

[5] Pascal Santi. L'ocytocine déroutante hormone de l'amour dans le monde du 5 septembre 2018, suppl. Science et Médecine.

[6] Lee, H.-J., Macbeth, A.H., Pagani, J.H. and Young, W.S. (2009) Oxytocin: The Great Facilitator of Life. Progress in Neurobiology, 88, 127-151.

https://doi.org/10.1016/j.pneurobio.2009.04.001

[7] Broad, K.D., Curley, J.P. and Keverne, E.B. (2006) Mother-Infant Bonding and the Evolution of Mammalian Social Relationships. Philosophical Transactions of the Royal Society B: Biological Sciences, 361, 2199-2214.

https://doi.org/10.1098/rstb.2006.1940 
[8] Numan, M. and Young, L.J. (2016) Neural Mechanisms of Mother-Infant Bonding and Pair Bonding: Similarities, Differences, and Broader Implications. Hormones and Behavior, 77, 98-112. https://doi.org/10.1016/j.yhbeh.2015.05.015

[9] Blanc-Petitjean, P. (2013) Ocytocine de synthese et travail spontane. Etude avantapres la mise en place d'un protocole a l'hopital Louis-Mourier. Gynecologie et obstetrique. dumas-00874840.

[10] Warkus, T., Denys, A., Hohlfeld, P. and Gerber, S. (2005) Priseen Charge de l'hémorragie du Post-Partum. Revue Médicale Suisse, 1, 30784.

[11] Ozier, Y. (1998) The Paradox of Disseminated Intravascular Coagulation. Annales Françaises d Anesthésie et de Réanimation, 17, 18s-22s.

https://doi.org/10.1016/S0750-7658(98)80101-9

[12] Recommandations pour la pratique clinique: Les hémorragies du post-partum Élaborées par le Collège national des gynécologues et obstétriciens français.

[13] Hidar, S., et al. (2004) The Effect of Placental Removal Method at Cesarean Delivery on Perioperative Hemorrhage: A Randomized Clinical Trial ISRCTN 49779257. European Journal of Obstetrics \& Gynecology and Reproductive Biology, 117, 179-182. https://doi.org/10.1016/j.ejogrb.2004.03.014

[14] Abdelmounaim, L.G., Biougnach, N., Rabea, B., Driss, H., Adil, T. and Said, L. (2020) A New Surgical Way to Face Postpartum Hemorrhage. Open Journal of Obstetrics and Gynecology, 10, 1147-1155. https://doi.org/10.4236/ojog.2020.1090108

[15] Subtil, D., Sommé, A., Ardiet, E. and Depret-Mosser, S. (2004) Postpartum Hemorrhage: Frequency, Cosequences in Terms of Health Status, and Risk Factors before Delivery. Journal de Gynécologie Obstétrique et Biologie de la Reproduction, 33, 9-16. https://doi.org/10.1016/S0368-2315(04)96644-6

[16] Parant, O., Guerby, P. and Bayoumeu, F. (2004) Spécificités obstétricales et anesthésiques de la prise en charge d'une hémorragie du post-partum (HPP) associée à la césarienne. Journal de Gynécologie Obstétrique et Biologie de la Reproduction, 43, 1104-1122. https://doi.org/10.1016/j.jgyn.2014.10.004

[17] Recommandations pour la pratique clinique: Les hémorragies du post-partum; Élaborées par le Collège national des gynécologues et obstétriciens français en 2014. 